\title{
The time relations of ECS induced amnesia'
}

ANNE GELLER AND M. E. JARVIK, ALBERT EINSTEIN COLLEGE OF MEDICINE, New York, N.Y. 10461

Mice were given electroconvulsive shock (ECS) after training in a passive avoidance task, and were tested for retention $1,2,6$, and $24 \mathrm{~h}$ later. Performance levels on the retention test, high $1 \mathrm{~h}$ after training gradually deteriorated at the other testing intervals.

Experiments designed to determine whether there is any recovery from the amnesia induced by ECS have yielded controversial results (Zinkin \& Miller, 1967; Luttges \& McGaugh, 1967). In all such experiments $S s$ were never retested before $24 \mathrm{~h}$. It was previously suggested by us (Geller \& Jarvik, 1968) that, since there is always some evidence, however slight, of conditioning as tested $24 \mathrm{~h}$ following a foot shock-ECS experience, maximum recovery from an ECS induced amnesia might have already taken place at that time. It then might be possible to demonstrate a more profound amnesia at earlier testing times and our failure to find the recovery of performance with time reported by others might be due to differences in experimental situation and animal species. Subjects

The Ss were 640 female CF1 mice, 6-8 weeks old, housed 8/cage.

Apparatus and Procedure

The conditioning apparatus was that described by Jarvik \& Kopp (1967) and consisted of a two compartment box in which the Ss could receive a $350 \mu \mathrm{A}$ foot shock (FS) for stepping from the small lighted compartment to a larger dark one. Ss escaped back to the light compartment from which they were removed. Retest trials were run with the same procedure.

Electroconvulsive shock was always administered transcorneally $20 \mathrm{sec}$ after the training trial using a Hans electroshock apparatus (2-C) which delivered $20 \mathrm{~mA}$ for $0.2 \mathrm{sec}$.

\section{EXPERIMENT 1}

Ss were divided into three experimental groups of 64 animals each. Group (FS) was given a training trial and returned to the home cage. Group (FS-ECS) was treated as Group (FS) but given ECS after the training trial, before being returned to the home cage. Group (ECS) was not exposed to the training situation but taken from the home cage, given ECS and returned. All groups were subdivided according to the time of testing which took place $1,2,6$, and $24 \mathrm{~h}$ after the FS, FS-ECS, or ECS experience.

Results

As can be seen in Fig. 1, Ss receiving FS show consistently high test latencies with no differences related to the time of testing. Ss receiving FS followed by ECS show initially high latencies gradually decreasing with time of test, with a significant ${ }^{2}$ difference between 1 and $24 \mathrm{~h}$ tests (Wilcoxon, 1964). The (ECS) group, compared with naive Ss shows lower $(p<.05)$ latencies at the $1 \mathrm{~h}$ test, but does not differ thereafter.

Comparing Groups (FS), (FS-ECS) and (ECS) with each other, it is found that (FS) and (ECS) are significantly different for all testing times. (FS-ECS) and (ECS) differ significantly for the 1, 2, and $6 \mathrm{~h}$ test times. (FS) and (FS-ECS) are not different at the 1 and $2 \mathrm{~h}$ tests but differ significantly at the 6 and $24 \mathrm{~h}$ tests.

The results of Group (FS-ECS) are the opposite of prediction if there were a more profound amnesia at the earlier times of testing and would suggest, on the contrary, that memory for the FS is better $1 \mathrm{~h}$ after a FS-ECS experience than $24 \mathrm{~h}$ later. The question arises, however, whether these findings reflect an action of ECS on the memory processes or whether they are a result of performance variables introduced by the FiS treatment itself. Group (ECS) does show a proactive effect of the treatment on performance in the direction of decreased rather than increased latencies at the earlier testing times. This is in agreement with the findings of Kopp et al (1967). If one examines closely the data for the (ECS) group, two opposite effects of the treatment are seen. One $h$ after
ECS the majority ( $85 \%$ ) of Ss show a decreased step-through latency, however, $15 \%$ of the (ECS) Ss show latencies of above 60 sec compared with only $4 \%$ of naive controls. This indicates that whilst activity is increased in most Ss $1 \mathrm{~h}$ after ECS, in some animals activity is depressed at this time. The proportion of Ss depressed should depend on the time after ECS at which the observation is made. One can assume that, following a foot shock, Ss are in an altered physiological state and that ECS in this situation might be potentiated with consequent prolongation of the postictal depression of activity.

Another possibility is that ECS causes a retrograde amnesia only for events preceding its administration by a few seconds, in this case the FS, but that events occurring outside this brief period, such as the initial exploration of the apparatus prior to the FS are retained. It is possible that the aversive after-effects of the ECS (the postictal period) could become conditioned to the apparatus. This conditioning might be expected to be quite tenuous and to decline fairly rapidly with time.

\section{EXPERIMENT 2}

To test these hypotheses, Experiment 1 was repeated with four additional groups. Group (TS) received a painful ( $1 \mathrm{~mA}, 1 \mathrm{sec})$ shock to the tail unassociated with the experimental apparatus; Group (TS-ECS) was given ECS after the tail shock. Group (NFS) was placed in the apparatus, allowed to step through without being shocked, and immediately removed; Group (NFS-ECS) was treated as (NFS), but given ECS after making the step-through response. All groups were divided into four subgroups according to the time of testing $1,2,6$, or $24 \mathrm{~h}$ after the various treatments. If the postictal effect were potentiated by a preceding shock one would expect an increase in the latencies of (TS-ECS) compared with (ECS), and if there were some conditioning to the apparatus of the unpleasant after-effects of ECS one would expect an increase in (NFS-ECS) as compared with the (ECS).

Results

The (FS), (FS-ECS) and (ECS) groups replicate the results of Experiment 1. Latencies of (TS-ECS) and (NFS-ECS) are higher than (ECS) at 1 h test (significant at $p<.05$ for (TS-ECS)), but they do not differ from each other. However, the conditioned Ss (FS-ECS), though not different from (TS-ECS) and (NFS-ECS) at $24 \mathrm{~h}$, do have significantly higher latencies at 1,2 , and $6 \mathrm{~h}$. Unexpectedly the (TS) and (NFS) groups show significantly higher latencies than naive $S s$ at the $1 \mathrm{~h}$ testing time.

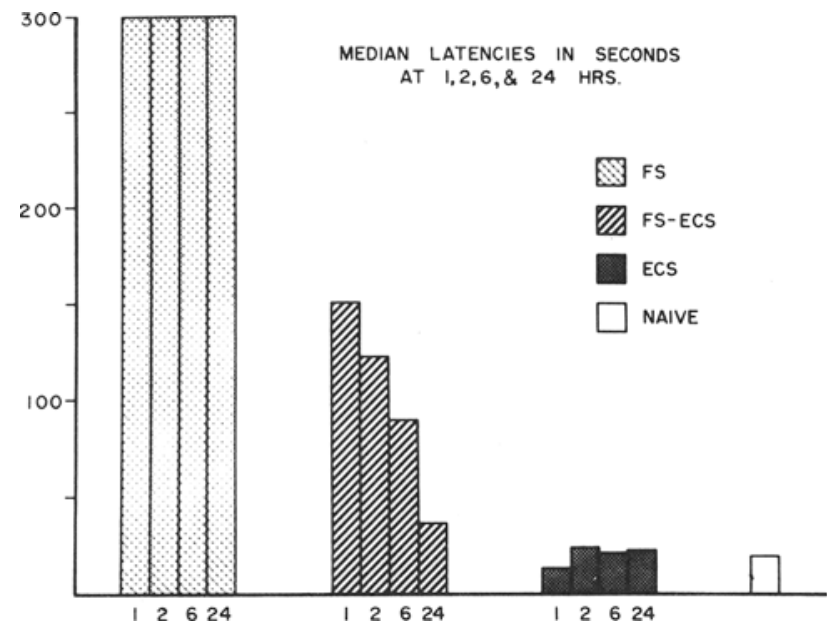

Fig. 1. Median step-through latencies of mice $1,2,6$, and $24 \mathrm{~h}$ after training. 


\section{DISCUSSION}

The results of Experiment 2 do not provide a clear explanation of the findings of Experiment 1. It is unlikely that association between the experimental situation and the aversive after-effects of ECS is a major factor as ECS following a nonshocked trial results in no higher latencies than ECS following a noncontingent tail shock. Since a preceding tail shock and an unshocked trial themselves produce an increase in latency, it can be assumed that there is some change in the physiological state of the animal following these experiences, and, it seems likely that all three circumstances (noncontingent tail shock, shocked, and unshocked trial) increase the arousal of the Ss, which might well be expected to alter their sensitivity to ECS. This explanation might well be expected to alter their sensitivity to ECS. This explanation alone, however, cannot account for the significantly higher latencies seen in the (FS-ECS) groups at the earlier testing times since the arousal should be similar following a tail shock or a foot shock. It might be that there is an interaction between the postictal depression and some residual conditioning in the (FS-ECS) group contributing to their higher latencies. The possibility that ECS acts on a long term process on analogy with the effect postulated for the protein inhibitors (Barondes, 1966) rather than affecting short-term memory as hitherto supposed, remains an interesting speculation, but one which can neither be substantiated nor refuted at the present time.

\section{REFERENCES}

BARONDES, S. H. Effect of inhibitors of protein and RNA synthesis on learning and memory. Excerpta Medica, 1966, 129, 208-211.

GELLER, A., \& JARVIK, M. E. Electroconvulsive shock induced amnesia and recovery. Psychon. Sci, 1968, 10, 15-16.

JARVIK, M. E., \& KOPP, R. An improved one-trial passive avoidance learning situation. Psychol. Rep., 1967, 21, 221-224.

KOPP, R., BOHDANECKY, Z., \& JARVIK, M. E. Proactive effect of a single ECS on step through performance of naive and punished mice. J. comp. physiol Psychol, 1967, 64, 22-25.

LUTTGES, M. E., \& McGAUGH, J. L. Permanence of retrograde amnesia produced by ECS. Science, 1967, 156, 408-410.

WILCOXON, F., KATTI, S. K., \& WILCOX, R. A. Critical values and probability levels for the Wilcoxon rank sum test and the Wilcoxon rank test. Lederle Laboratories Division, American Cyanamid Co., August, 1964.

ZINKIN, S., \& MILLER, A. J. Recovery of memory after amnesia induced by ECS. Science, 1967, 155, 102-104.

NOTES

1. Supported by PHS Grant MH 05319 and an Interdepartmental Institute for Training in the Neurologic and Behavioral Sciences Grant.

2. All significances at $p<.01$ unless otherwise stated. 